\title{
Support Trusses for Large Precision Segmented Reflectors: Preliminary Design and Analysis
}

Timothy J. Collins and W.B. Fichter

March 1989

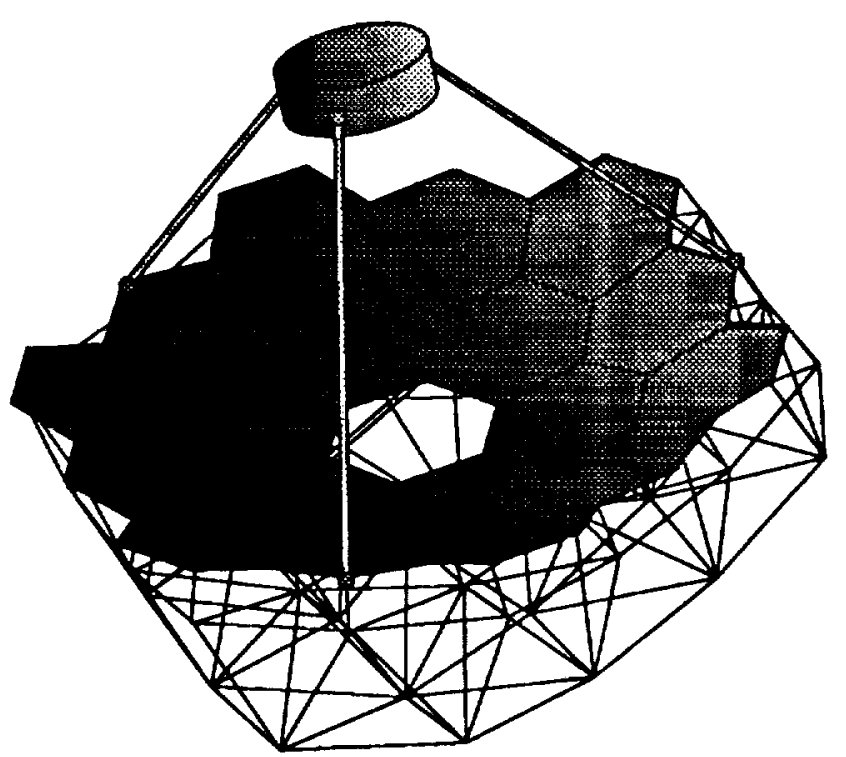


$1 \times$

- 


\title{
SUPPORT TRUSSES FOR LARGE PRECISION SEGMENTED REFLECTORS: PRELIMINARY DESIGN AND ANALYSIS
}

\author{
Timothy J. Collins \\ W. B. Fichter
}

\section{INTRODUCTION}

The Precision Segmented Reflector (PSR) program is a part of a larger NASA research and development program known as the Civil Space Technology Initiative (CSTI). The goal of PSR is to develop technology that will enable the design of large diameter, lightweight, highly accurate, orbiting astronomical instruments. One example of a PSR application is the Large Deployable Reflector (LDR), an astronomical observatory that would operate in the infrared and far infrared regions of the spectrum. Because the LDR program has existed for some time, many preliminary design goals for this reflector are well defined. As a result, LDR is often cited as an example when discussing gencral PSR issues. One possible configuration for LDR is shown in Figure 1. It has a segmented passive primary reflector surface, 20 melers in diameter and supported by a doubly curved truss structure. Additional information related to the model in Figure 1 will be discussed later. Unlike LDR, PSR is generic in the sense that it should have a wide range of future applications, some of which are presently undefined.

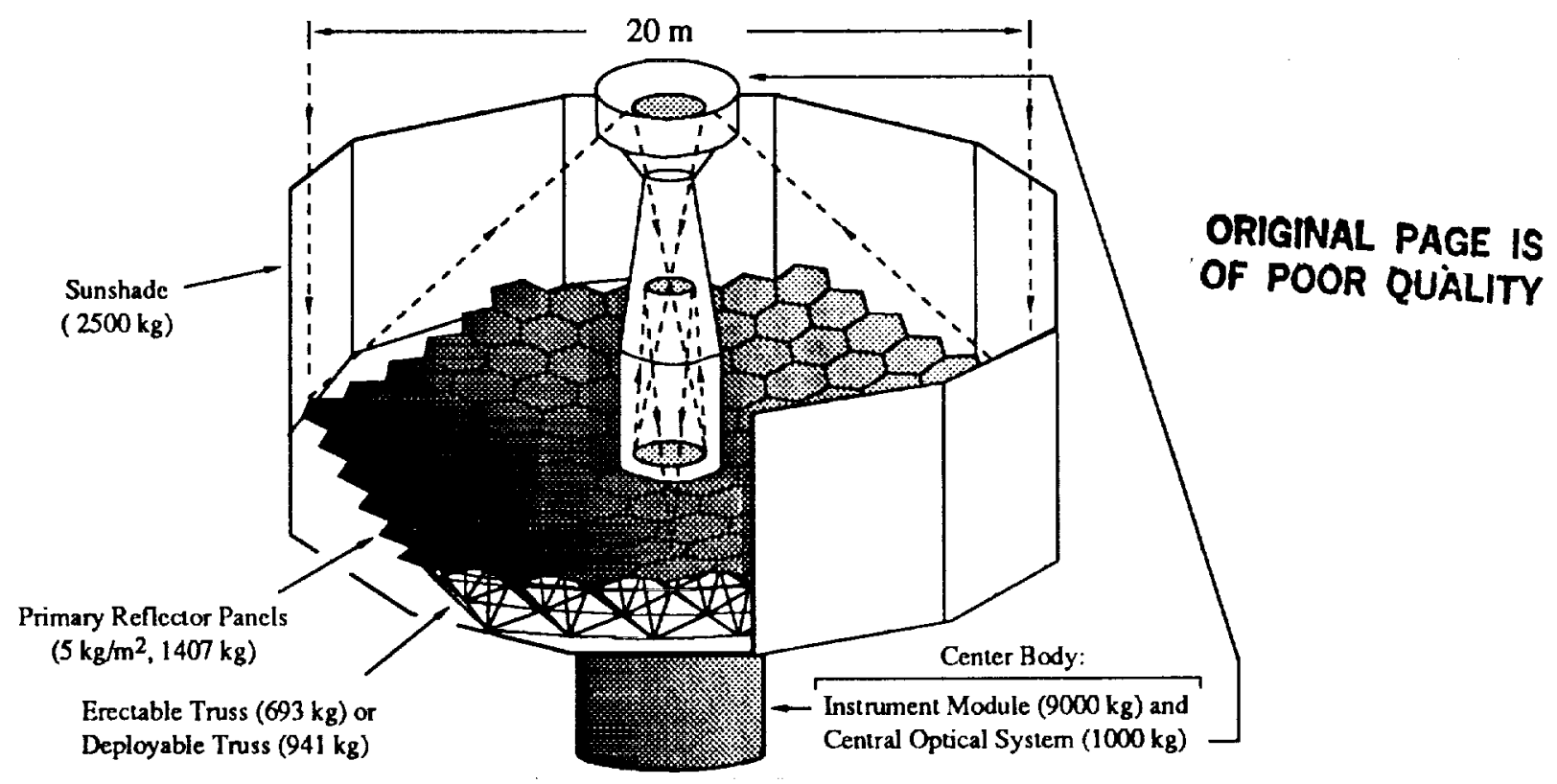

Figure 1. Large Deployable Reflector (LDR) model used for analysis of large PSR support trusses.

Future space observatories, such as LDR, promise to be larger than current antenna systems, while demanding greater reflector surface accuracy. Their large size will preclude transportation to space in an assembled configuration; thus, suppon 
structures for large reflectors will either be assembled or deployed on-orbit. Assembly in space requires that the structural components be easily handled and assembled. A deployable structure must package compactly and deploy reliably into a correct and stable geometry. The issues of assembly and deployment must be considered in light of the requirement for lightweight, stiff, and accurate structures.

NASA's lead center for the PSR program is the Jet Propulsion Laboratory (JPL). The total PSR effort is subdivided into three tasks: integration and testing, reflector panel technology, and primary structures. For implementation of the PSR program, NASA's Langley Research Center (LaRC) is a partner in the overall effort. LaRC's role is related to the primary structures and panel technology tasks of PSR. This paper, which explores only the structures task, begins by outlining the PSR primary structures plan at Langley Research Center. Current geometries and design considerations for erectable and deployable reflector support structures are discussed. Support truss requirements and goals for PSR are given. The results of static and dynamic analyses of a prototype 4-meter diameter structure are presented. In addition, similar results are presented for two 20-meter-diameter support trusses. Implications of the analyses for the PSR program are considered and the formulation and limitations of current PSR finite element models are discussed.

\section{LANGLEY RESEARCH CENTER'S PRIMARY STRUCTURES PROGRAM}

The PSR primary structures activity at LaRC can be divided into three principal areas: deployable support structures, crectable support structures, and assembly studies, as shown in Figure 2. The deployable and erectable support structures activitics involve a variety of tasks which include but are not limited to: concept studies, strut and joint technology, model development, and structural analysis. Assembly studies are aimed at developing efficient methods for truss assembly, panel attachment, and utilities installation. Other activities at LaRC which are not part of the PSR program but are closely related to it, include automáted robotic assembly and a definition study for a future flight experiment.

Current efforts at LaRC are concentrated on the design and fabrication of a prototype 4-metcr-diameter erectable truss that will serve as the support structure for the JPL Test Bed, which is illustrated in Figure 3. The Test Bed is the first in a scquence of structures to be fabricated and tested as part of the PSR program. This first structure is expected to provide initial insight into PSR-related issucs such as component integration, component operation, and system structural characteristics. The Test Bed structure will accommodate a parabolic reflector surface with a focal length of 2.4 meters. It will be used by LaRC and JPL to detcrmine the characteristics of a PSR-type structure, and to develop and refine testing capabilities. The Test Bed will represent LaRC's first attempt at building a structure that meets PSR accuracy requirements (discussed in section 4 of this paper). In addition to the Test Bed, which is scheduled to be delivered to JPL in the summer of 1989, LaRC plans to build a similar structure of twice the diameter. This structure will be used at LaRC as a test article in surface accuracy and structural behavior studies similar to those planned for the Test Bed truss. Note that the additional information shown in Figure 3 for the Test Bed will be discussed later. 


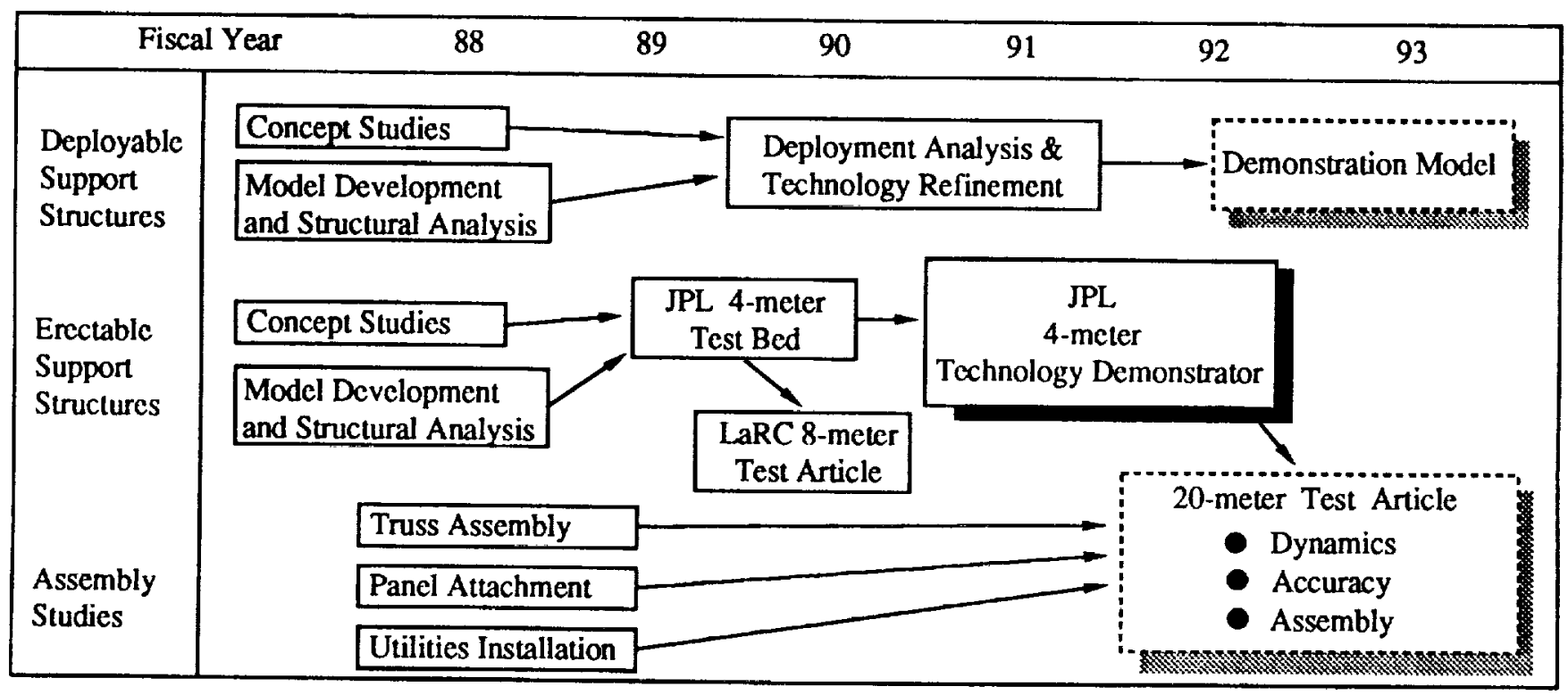

Figure 2. The PSR primary structures plan at NASA Langley Research Center.

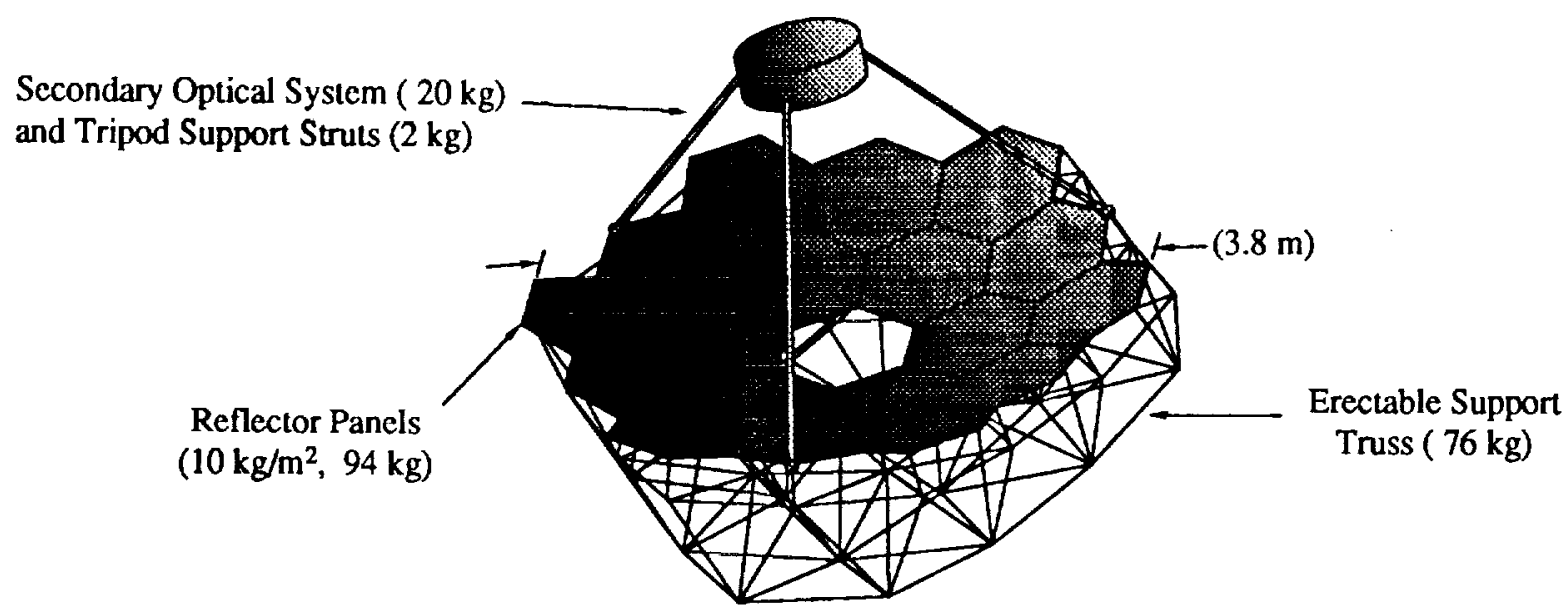

Figure 3. Test Bed model.

The Test Bed experience should lead to improved structures, the first of which is expected to be the JPL Technology Demonstrator (Figure 2). This structure will be similar in size and geometry to the Test Bcd, but is expected to use higher quality component materials, and to be compatible with refined system objectives. Once all relevant technologies for PSR have been amply examined using the the 4-meter structures, it may be desirable to fabricate and test a full scale, 20-meterdiameter test article. This large structure would be useful in finalizing and validating the technologies required for large PSR 
applications, such as LDR. The PSR program, which ends in 1991, currently does not contain the funding for such a large project.

\section{SUPPORT TRUSS CONCEPTS FOR PRECISION SEGMENTED REFLECTORS}

Figure 4 depicts a "two-ring" and a "five-ring" support truss with attached reflector panels. The terms two-ring and five-ring refer to the number of circumferential rings of hexagonal panels that will be supported by the truss. The center pancl in each reflector in Figure 4 has been removed along with several of the underlying support struts, leaving an opening to accommodate instrumentation modules. The Test Bed is designed to be a two-ring system with a maximum diameter of approximately four meters. It is anticipated that a 20-meter-diameter support structure suitable for LDR would have five rings of panels. Through conceptual design studies at LaRC and a contract with Astro Aerospace Corporation, concepts have been developed that would allow support trusses like those in Figure 4 to be either of erectable or deployable design. Brief descriptions of these concepts are presented here.

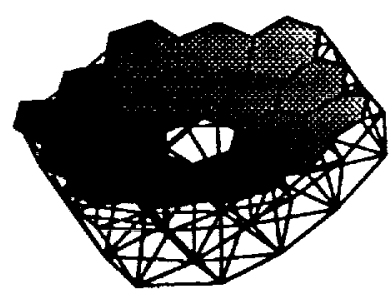

Two-king

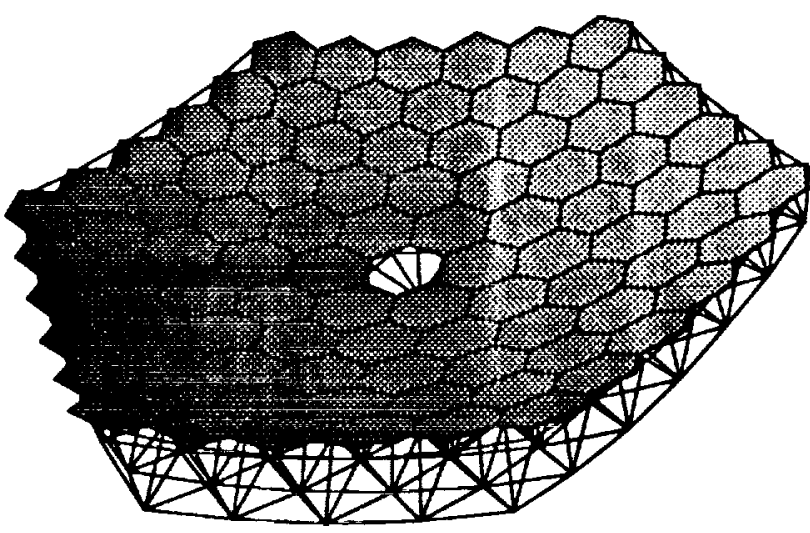

Five-Ring

Figure 4. Typical two-ring and five-ring PSR support structures with reflector panels.

\subsection{Deployable support truss concept}

One concept for a PSR structure that would deploy after being placed in orbit is shown in Figure 5. This concept was initiated and is described by Hedgepeth ${ }^{1}$. This deployable design is referred to as a "hybrid" because it contains two types of deployable structures. As shown in Figure 5, six "single-folding" radial truss beams at sixty degrec increments around a central hexagonal opening are fully integrated with six sections of "double-folding" truss structure. Each single-folding beam unfolds radially, while its width remains constant. The double-folding scctions of the hybı d truss unfold simultaneously in both the radial and the circumferential directions during deployment. The entire struclure packages as one unit and deploys synchronously to accommodate a parabolic reflector surface geometry. 


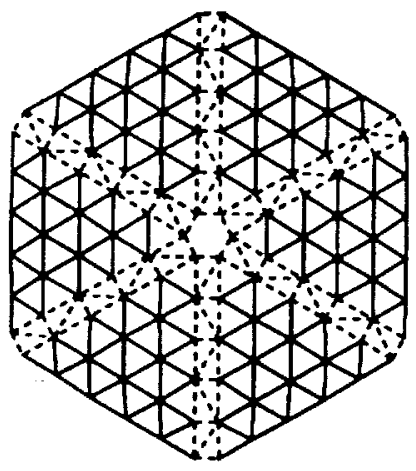

Entire Truss (Plan Vicw)

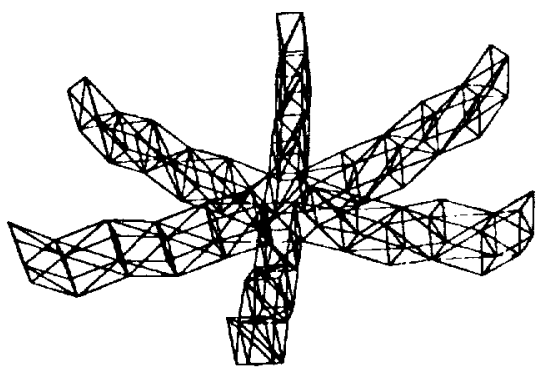

Single-Folding Beams

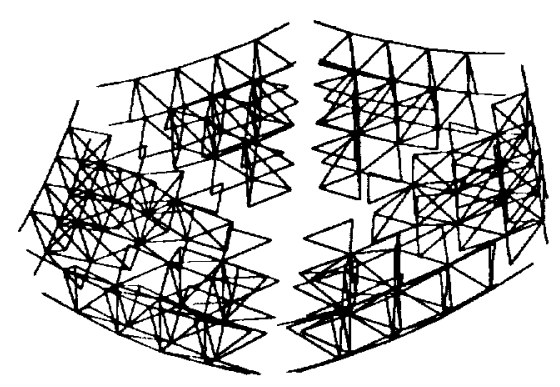

Double-Folding Truss

Figure 5. Five-ring deployable hybrid truss concept for a PSR support structure.

Although it is possible to create a deployable support structure using only double-folding sections of truss, incorporation of the single-fold beams provides a central opening which can accommodate an instrument module or other center body. Figure 6 shows the deployment sequence of a three-bay section of a typical single-folding beam. It should be noted that in the fully deployed configuration the middle bays on each side of the center body remain horizontal. Extension structure has becn added to these bays to accommodate the attachment of a parabolic reflector surface. The extension structure is required to climinate analytically predicted lock-up problems during deployment. Additional information on the hybrid deployable truss design is contained in reference 1 .

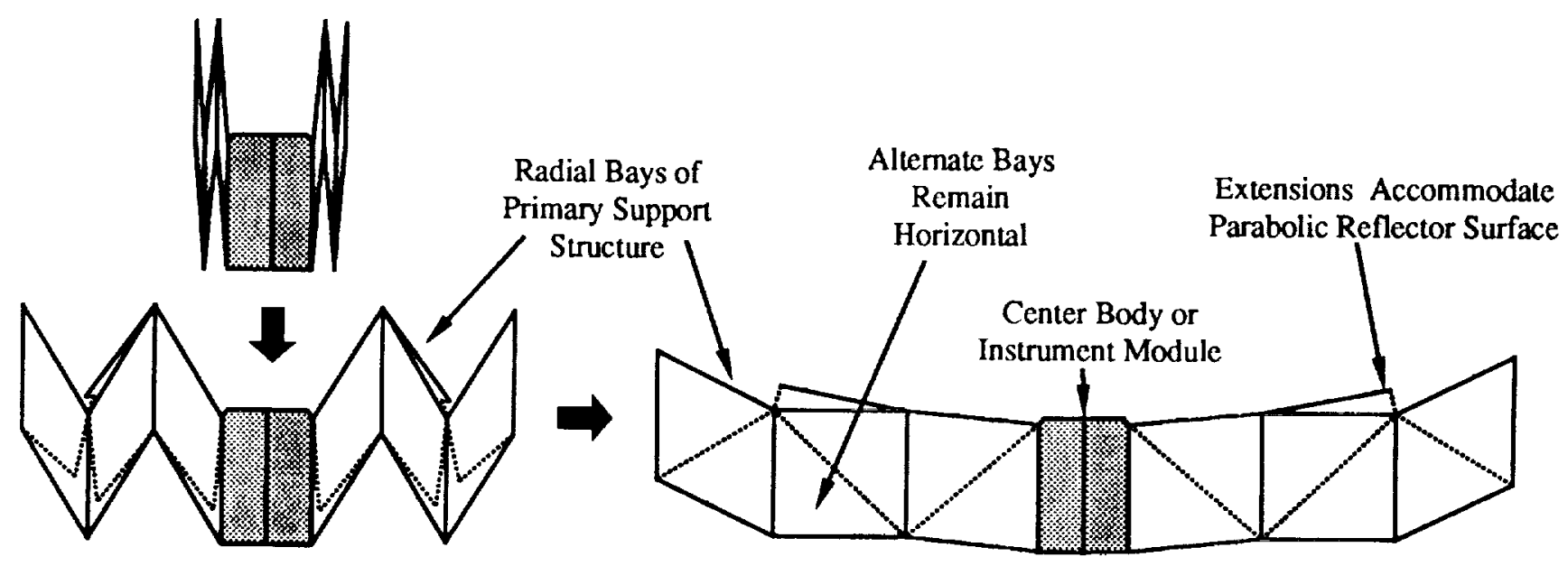

Figure 6. Hybrid truss deployment sequence. 


\subsection{Erectable support truss concept}

One concept for an crectable PSR support structure is the tetrahedral truss shown in Figure 7. In a planar tetrahedral truss, all struts can be of equal length. However, in a doubly curved truss, this is not possible. Figure 8 shows an exploded view of a two-ring erectable tetrahedral truss structure with reflector panels. The structure is composed of 150 struts and 45 strut connecting nodes. The "standoffs" shown beneath the reflector panels in the figure represent the distance between the reflector surface and the primary truss. This distance is provided to accommodate the panels as well as actuators or other hardware that might be required to attach the panels to the truss. For the erectable truss designs developed by LaRC, the core struts are of equal length, while the struts in the upper and lower surfaces vary in length. Like the hybrid deployable truss, the crectable tetrahedral truss easily accommodates a central opening. Every strut of the erectable truss contains manually operated joints which allow for easy replacement of any strut with another of the same length.

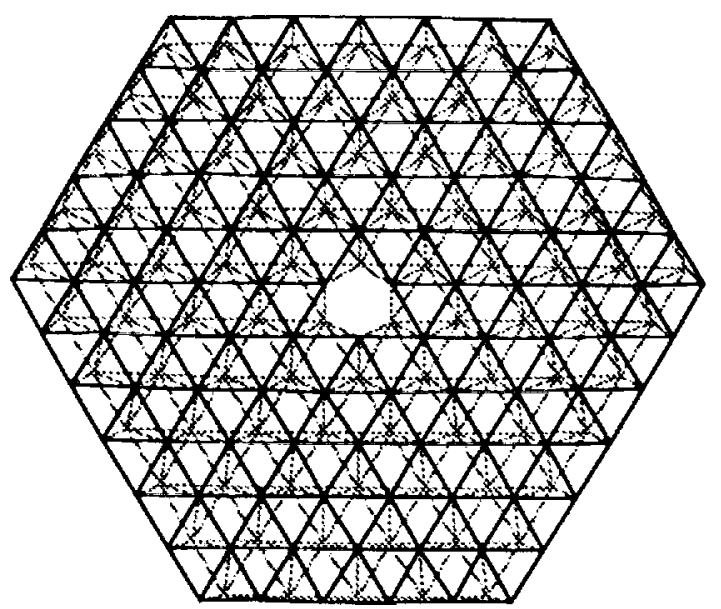

Plan View (upper surface in bold)

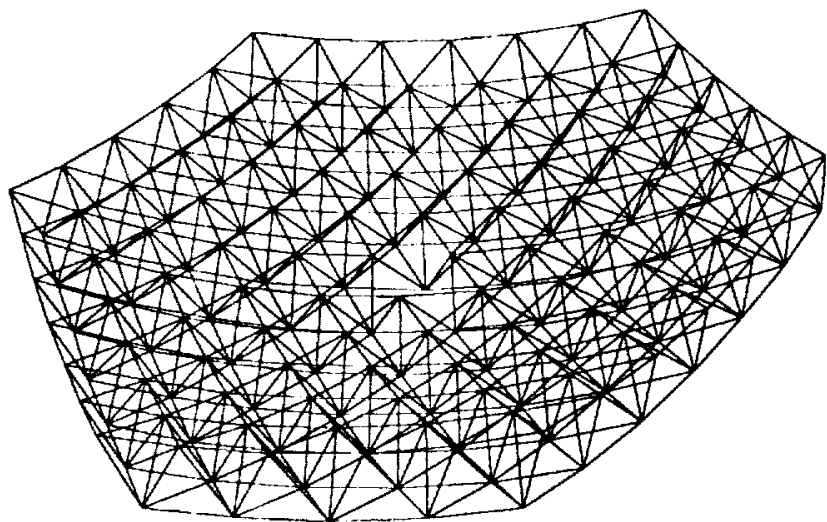

Oblique View

Figure 7. Five-ring tetrahedral truss for an crectable PSR support structure.

\subsection{Issues releyant to the use of erectable or deployable support trusses}

The deployable counterpart to the erectable structure in Figure 8 is shown in Figure 9. The erectable and deployable trusses in the figures have been designed to accommodate the same set of reflector panels. While the number of panels is the same, the total number of struts (294) and nodes (84) is significantly greater in the deployable truss, in fact by nearly a 2 to 1 ratio. This part-count ratio declines as more rings are added, but the difference in total strut and node count remains 
significant. For example, a five-ring erectable truss would have 789 struts and 198 nodes, while a similar deployable truss would have 1158 struts and 300 nodes. Differences in the numbers of struts and nodes may be important when considering mass, cost, and assembly requirements for future PSR applications.

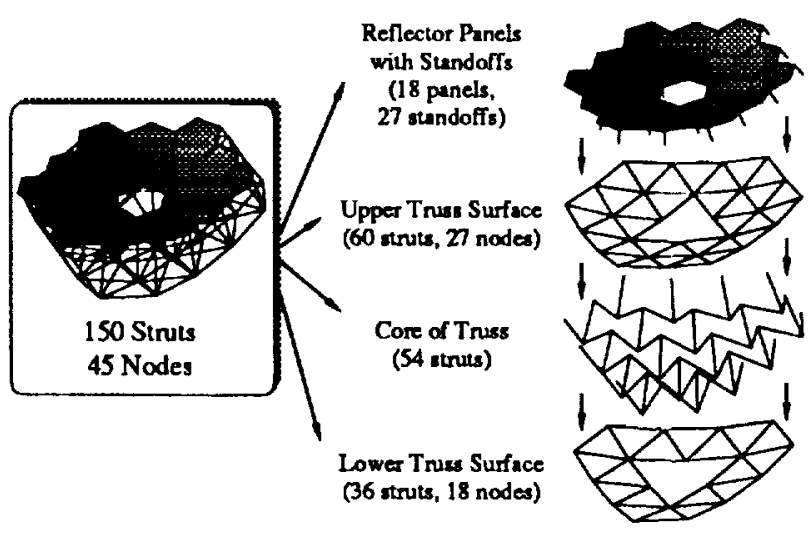

Figure 8. Exploded two-ring erectable truss.

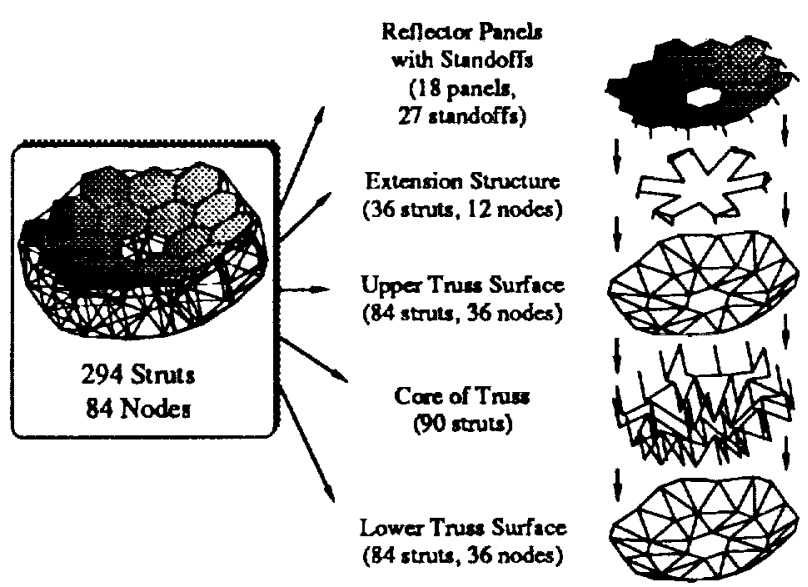

Figure 9. Exploded two-ring deployable truss.

An advantage of a deployable support truss is the fact that it would reduce the amount of on-orbit assembly time required. Also, such a truss could be deployed in high Earth orbits which are inaccessible to the Space Shuttle. Whether a primary support truss is deployed or erected, the reflector panels must be mounted to the truss surface. The complexity and accuracy required of the reflector surface may require that the panels be manually attached by astronauts. Estimates of the time necded to erect a complete PSR structure suggest that the truss assembly time may be significantly less than the panel attachment timc $^{2}$. Hence, the time saved by using a deployable support truss may be insufficient to warrant the expected additional expense and complexity. Much of the technology required for high-performance erectable structures has been developed through work on space station hardware. These considerations, along with the fact that the technology for the reliable deployment of stiff, accurate, and dimensionally stable structures has not been amply demonstrated, have led LaRC to concentrate on erectable structures for near-term applications. The further development of deployable structures and robotic assembly technology may make altemate options available in the future.

\section{SUPPORT TRUSS REOUIREMENTS FOR PSR APPLICATIONS}

In this section, the fundamental requirements for the Test Bed and for larger PSR support trusses are summarized. These requirements were arrived at by evaluating future PSR objectives and have been generally agreed upon by members of the JPL and LaRC design teams. The mass goal for PSR support structurc is an areal density of $5 \mathrm{~kg} / \mathrm{m}^{2}$ or less, with an upper limit of $10 \mathrm{~kg} / \mathrm{m}^{2}$. The same areal density goal and upper limit apply to the panels (including panel mounting hardware) and 
to their associated utilities such as actuators or electronics. Thus, the areal density goal for all components (truss, panels, and panel utilities) is $15 \mathrm{~kg} / \mathrm{m}^{2}$. The surface accuracy goal for a PSR truss structure is an ms surface error no greater than $100 \mu \mathrm{m}$ in a space environment. For this paper, rms error was determined from the components of error normal to a parabola that best fits a distorted surface. In addition to the above requirements, the Test Bed must accommodate a secondary optical system with a mass of $20 \mathrm{~kg}$ (see Figure 3). To minimize the blockage of radiation striking the reflector surface, the maximum width of each secondary support strut was set at $3 \mathrm{~cm}$. Larger PSR support structures may have to accommodate additional components such as a sunshade, an optical system, or a massive center body, in addition to the reflector panels.

Stiffness related quantities for PSR structures include deflections under 1-g and in-space operational loads, as well as nalural frequencies. The surface accuracy goal for the Test Bed under 1-g loading is to locate the truss nodes to within $100 \mu \mathrm{m}$. This would be within JPL's expected operating range for the PSR panel positioning actuators. Pointing and attitude control maneuvers result in angular accelerations (or operational loadings) of the primary structure. Although the Test Bed does not have any operational loading requirements, a typical operating load for PSR can be estimated by using the LDR-baseline requirements which allow for slewing velocitics of 20-50 degrees per minute ${ }^{3}$. The torque available to attain maximum slewing velocity will be on the order of $250 \mathrm{~N}-\mathrm{m}$. Using this value for the available torque, and estimating LDR inertia properties, it is found that the structure may undergo slewing angular accelerations approaching $8 \times 10^{-4} \mathrm{rad} / \mathrm{sec}^{2}$ or 0.8 $\mathrm{mrad} / \mathrm{sec}^{2}$. Based on this, a conservative estimate for required slewing acceleration would be $1.0 \mathrm{mrad} / \mathrm{sec}^{2}$. This value has been used in the analyses of reference 1 and in this paper. The dynamic requirements for cither the Test Bed or PSR in general are not well defined. The functional requirements for PSR state that the Test Bed should have LDR-like dynamic characteristics. For large PSR structures such as LDR it is desirable to make the structure as stiff as possible. Doing so reduces undesirable coupling between the truss and control system modes, and decreases damping time when truss modes are exciled.

\section{MODELING AND ANALYSIS OF THE PSR TEST BED}

As stated previously, the Test Bed will serve as a first test article for developing and validating technology required for future PSR activities. Some details of current work at LaRC which is related to the Test Bed support truss are presented here.

\subsection{Test_Bed descriotion}

A diagram of the Test Bed as currently envisioned was shown in Figure 3. The structure is a two-ring erectable truss having a total mass of $76 \mathrm{~kg}$. Most of this mass $(61.6 \mathrm{~kg}$ or $81 \%)$ is contained in aluminum nodes and joints. The remaining mass $\left(14.4 \mathrm{~kg}\right.$ ) is contained in graphite/epoxy tubes. The areal density of the Te $i t$ Bcd truss is $8.1 \mathrm{~kg} / \mathrm{m}^{2}$, greater than the PSR goal of $5 \mathrm{~kg} / \mathrm{m}^{2}$ but within the upper limit of $10 \mathrm{~kg} / \mathrm{m}^{2}$. The tube are composed of $\mathrm{T} 300 / 5208$ 
graphite/epoxy fabricated from a $\$ 10^{\circ}$ lay-up. The tubes have a diameter of $2.54 \mathrm{~cm}$ and a wall thickness of approximately $1.5 \mathrm{~mm}$. The Test Bed will be built to accommodate reflector panels and actuators with a combined areal density of 10 $\mathrm{kg} / \mathrm{m}^{2}$ and a secondary optical system of $22 \mathrm{~kg}$ mass. However, only one reflector panel of optical quality will be fabricated for technology validation. The remaining panels will be dummy masses to be used for static and dynamic testing purposes. The Test Bed reflector surface will have a maximum diameter of $3.8 \mathrm{~m}$ and a total reflector surface area of $9.4 \mathrm{~m}^{2}$. All core struts of the Test Bed truss will have a length of $81.4 \mathrm{~cm}$. This length was chosen because it maximizes the total area of the reflector surface without requiring a panel dimension greater than $90 \mathrm{~cm}$, a limit specified by JPL based on current panel fabrication capabilities.

\subsection{Test Bed finite element model}

To analyze the structural characteristics of the Test Bed, a finite element model of the truss, panels, and secondary optics was created. The node locations for the model were derived from the geometry of the Test Bed. Rod elements (axial stiffness only) were used for the primary truss structure, while bar elements (axial and bending stiffness) were used for the secondary tripod support struts (Figure 3). The graphite/epoxy tubes were assumed conservatively to have a modulus of elasticity of $10.3 \times 10^{10} \mathrm{~N} / \mathrm{m}^{2}$ (15 million psi). For the $\pm 10^{\circ}$ lay-up indicated earlier, a higher modulus is possible but no tubes have been fabricated and tested as of this writing. The value used in the analyses allows for the possibility of some resin richness in the tubes. The density of T300/5208 graphite/epoxy was taken to be $1522 \mathrm{~kg} / \mathrm{m}^{3}$.

The configuration of the tube, joints, and nodes for a typical erectable Test Bed strut is shown in Figure 10. The distance between the node centers is referred to as the strut length, $\mathrm{L}_{\mathbf{8}}$. This distance is occupicd by the tube, two joints, and two node halves. The tube length is denoted by $L_{\imath}$, while the total length occupied by the aluminum joints and nodes is $L_{j}$.

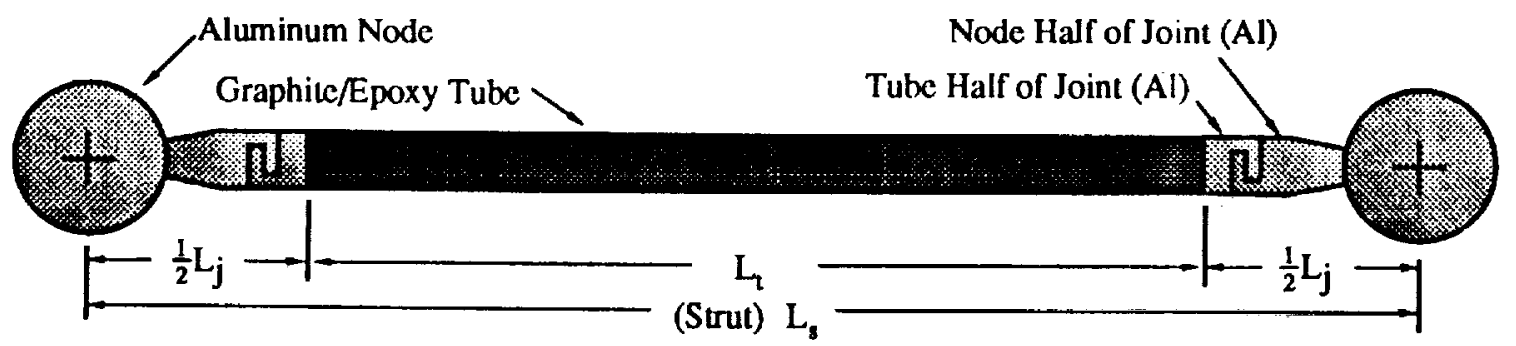

Figure 10. Tube, node, and joint configuration for an erectable Test Bed strut.

To include the aluminum joints and nodes in the Test Bed finite element model, the following approach was taken. The mass of each joint $(.168 \mathrm{~kg})$ and each node $(.248 \mathrm{~kg})$ was included by placing concentrated masses at the node center locations. Each strut with its associated tube, joints, and node halves was treated as a single element having an effective 
axial stiffness $\left(E A / L_{3}\right)_{\text {eff }}$, where the subscript "eff" denotes an effective axial stiffness of the components acting in series. If the stiffness of each joint/node section (labeled $\mathrm{L}_{\mathrm{j}} / 2$ in Figure 10) is known, the effective stiffness can be found from the following equation:

$$
\left(\frac{E A}{L_{s}}\right)_{d f}=\left[\frac{L_{j}}{(E A)_{j}}+\frac{L_{l}}{(E A)_{t}}\right]^{-1}
$$

In this equation (EA) $)_{j}$ and $L_{j}$ apply to the joint/node combination, while (EA), and $L_{t}$ apply to the graphite/epoxy tube. For the Test Bed, $(E A)_{j}$ was determined experimentally to be $8.9 \times 10^{6} \mathrm{~N}\left(2.0 \times 10^{6} \mathrm{lbf}\right)$, while $\mathrm{L}_{\mathrm{j}}=26.3 \mathrm{~cm}$ for all joints in the structure. For any strut, $L_{\mathrm{l}}=\mathrm{L}_{\mathrm{s}}-\mathrm{L}_{\mathrm{j}}$. Using the values given previously for the graphite/epoxy tubes, $(E A)_{t}=$ $11.8 \times 10^{6} \mathrm{~N}$. Considering a core strut as an example $\left(\mathrm{L}_{\mathrm{z}}=81.4 \mathrm{~cm}, \mathrm{~L}_{4}=55.1 \mathrm{~cm}\right)$, use of Equation 1 gives $\left(\text { EA/ } / \mathrm{L}_{\mathrm{s}}\right)_{\text {eff }}=$ $1.3 \times 10^{7} \mathrm{~N} / \mathrm{m}$. This value is the effective stiffness of the graphite/epoxy tube and aluminum joints and nodes treated as a single clement. The effective stiffness is approximately $10 \%$ less than that of a graphite /epoxy tube of length $\mathrm{L}_{2}$ (or $10 \%$ less than the stiffness that would be used if the aluminum nodes and joints were ignored). For the Test Bed truss, effective stiffnesses were determined for each truss member based on its strut length $L_{3}$. The effective stiffnesses were obtained by inputting an effective area, $A_{\text {eff }}$, that would yield the correct value of $\left(E A / L_{8}\right)_{\text {eff }}$ for each strut.

Once the strut (or element) effective axial stiffness was input to the model, an effective density was determined that would lead to the correct mass for each strut. For the mass of each element, as calculated during a finite element analysis, to equal the actual mass of the graphite/epoxy tube between any two nodes, the following equation must hold:

$$
\rho_{\text {eff }}=\frac{\rho_{t} A_{t} L_{t}}{A_{\text {eff }} L_{s}}
$$

where $A_{t}$ and $\rho_{t}$ are the area and density of the graphite/epoxy tube and $\rho_{\text {eff }}$ is the effective density input to the finite element model. As was done for the nodes and joints, the mass of the reflector pancls was also incorporated by placing concentrated masses at the surface nodes of the truss structure, with $1 / 3$ of cach pancl mass distributed to cach of its three support nodes (cach hexagonal reflector pancl will be supported at three of its six vertices). The mass of actuators was incorporated by adding their areal density $\left(5 \mathrm{~kg} / \mathrm{m}^{2}\right)$ to the areal density of the reflector panels and motnting hardware $\left(5 \mathrm{~kg} / \mathrm{m}^{2}\right)$. The flexibilitics of these components were not included in the model.

The secondary optical system was included in the finite element model by placing a concentrated mass of $20 \mathrm{~kg}$ at the focal point of the reflector. The inertia properties of this mass were assumed to be those of a cylinder $15 \mathrm{~cm}$ in diameter and $10 \mathrm{~cm}$ in length. The tripod support struts were modeled as beam elements with the same material properties as the truss 
struts, pinned at the truss connection points, and clamped to each other at the focal point. These struts were $2.9 \mathrm{~m}$ in length and, to comply with the maximum blockage requirement, were assumed to have a diameter of $3 \mathrm{~cm}$.

\subsection{Test Bed analysis}

This section contains the results of two analyses of the Test Bed: static deflections under gravity loading, and natural frequencies. The support conditions are defined, followed by the analysis results. The Test Bed finite element model was constructed and analysis results were interpreted using the pre/post-processor I-DEAS Supertab*. The analyses were conducted using MSC/NASTRAN** .

5.3.1 Test Bed support conditions. The objective of this study was to predict the static and dynamic behavior of the Test Bed during ground test conditions. The planned ground tests will consist of static and dynamic tests as well as surface accuracy measurements. During these tests, the Test Bed will be mounted to a ground support which attaches at the lower surface of the truss. For the analyses presented here, four support conditions were considered. These are shown in Figure 11. For two of the support conditions, the truss was mounted at the innermost nodes on the lower surface. For the remaining two support conditions, the truss was mounted at the intermediate nodes on the lower surface. Supporting the truss at the inner nodes would allow for a smaller and simpler mounting fixture. Using the intermediate nodes should result in less static deflection of the structure but would require a larger mounting fixture that accommodates the truss curvature. For each mounting configuration, both a restrained and a radially free support condition were applied. For the restrained condition each node was fixed in three degrees of freedom (an axial rod element has no moment-bearing capability). For the radially free condition, each node was allowed to move in the radial direction, with respect to the origin or center of the lower Iruss surface, while being fixed in the remaining two degrees of freedom. A radially free support condition might be desirable because it is a statically determinate boundary condition.

5.3.2. Static deflections of the Test_Bed under gravity loading. To characterize the behavior of the Test Bed truss alone, the secondary optical system was removed from the model for the initial static analyses. Figure 12 shows the results for the calculated static deflections due to gravity loading $(1-\mathrm{g})$ for each of the four support conditions. The vertical scale on the left corresponds to the solid curves which indicate the maximum $Z$-deflection of the upper truss surface (the $Z$-axis corresponds to the optical axis). The vertical scale on the right side corresponds to the dashed curves which show the ms error (as defined in section 4) of the upper truss surface. The deflections and ms surface errors are plotted as functions of the areal density of the panels and their mounting hardware. As expected, the results show that the upper surface is distorted

\footnotetext{
* SDRC I-DEAS and Supertab are registered trademarks of Structural Dynamics Research Corporation, 2000 Eastman Drive, Milford, Ohio 45150.

** MSC/NASTRAN is a trademark of the MacNeal-Schwendler Corporation, 815 Colorado Boulevard, Los Angeles, California 90041.
} 
less when the truss is supported at the intermediate nodes than when it is supported at the inner nodes. The ms surface error is approximately $60 \%$ less than for the inner node support cases. This is true for both the restrained and radially free support conditions. The results in Figure 12 indicate that an intermediate support may be preferable if minimizing surface deflection is of primary importance. Furthermore, if an intermediate support is used, deflection results are relatively insensitive to the difference between the radially free and restrained support conditions.

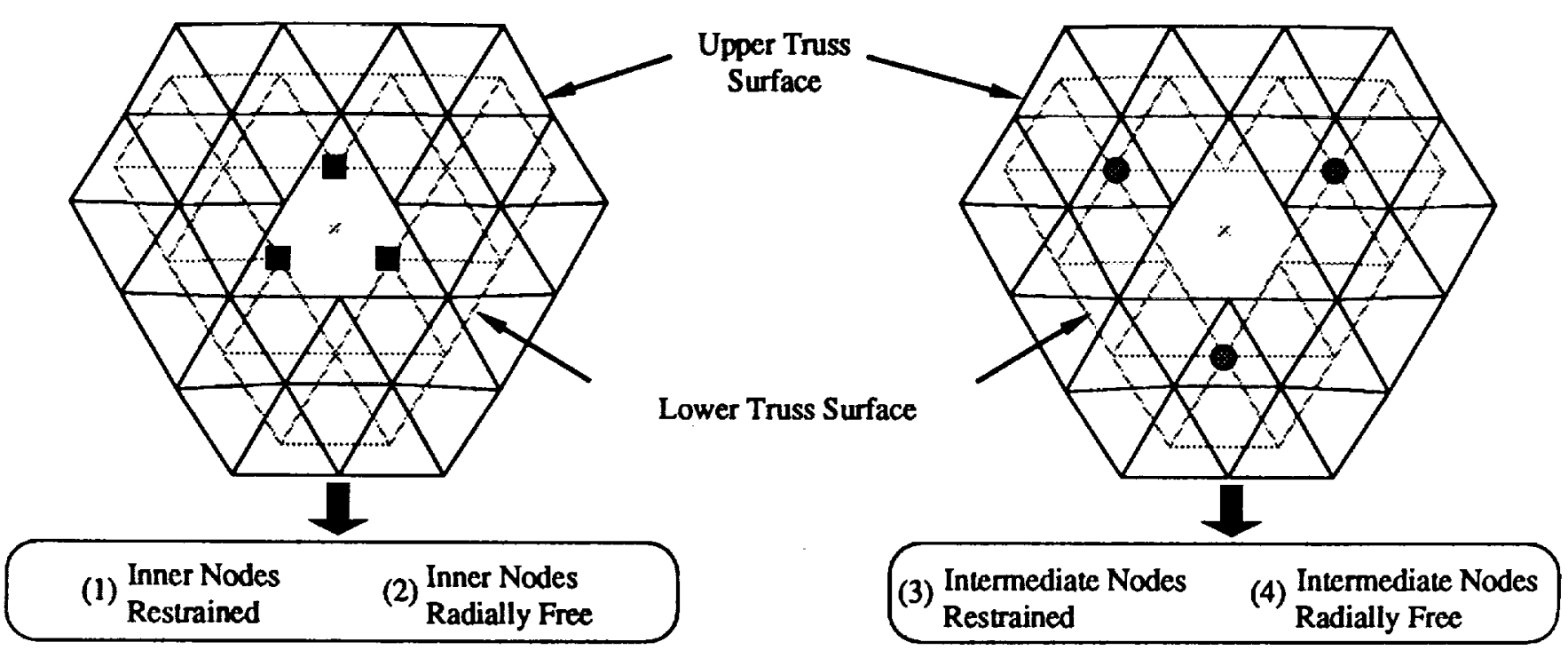

Figure 11. Four support conditions used for Test Bed analysis.

Gravity load analyses (not shown in Figure 12) were also performed for the Test Bed with the secondary optical system included. The secondary optics and its tripod support add $22 \mathrm{~kg}$ of mass to the structure, and this additional mass increases both the maximum- $Z$ deflection and the rms surface error. For the restrained intermediate nodes case and $10 \mathrm{~kg} / \mathrm{m}^{2}$ panels and actuators, the maximum Z-deflection increased from $49.5 \mu \mathrm{m}$ (as shown in Figure 12) to $55.5 \mu \mathrm{m}$, an increase of 12\%, and the rms surface error increased from $11.6 \mu \mathrm{m}$ to $15.5 \mu \mathrm{m}$, an increase of $34 \%$. The larger increase in ms surface error is due to the fact that the secondary optics tripod support causes the truss to deform nonuniformly. For all of the static analyses performed with the intermediate nodes supported, both the maximum and ms errors were within the $100 \mu \mathrm{m}$ design goal of PSR. However, the maximum deflections are still of interest because they may represent a significant portion of the actuator range expected to be available for surface correction. 


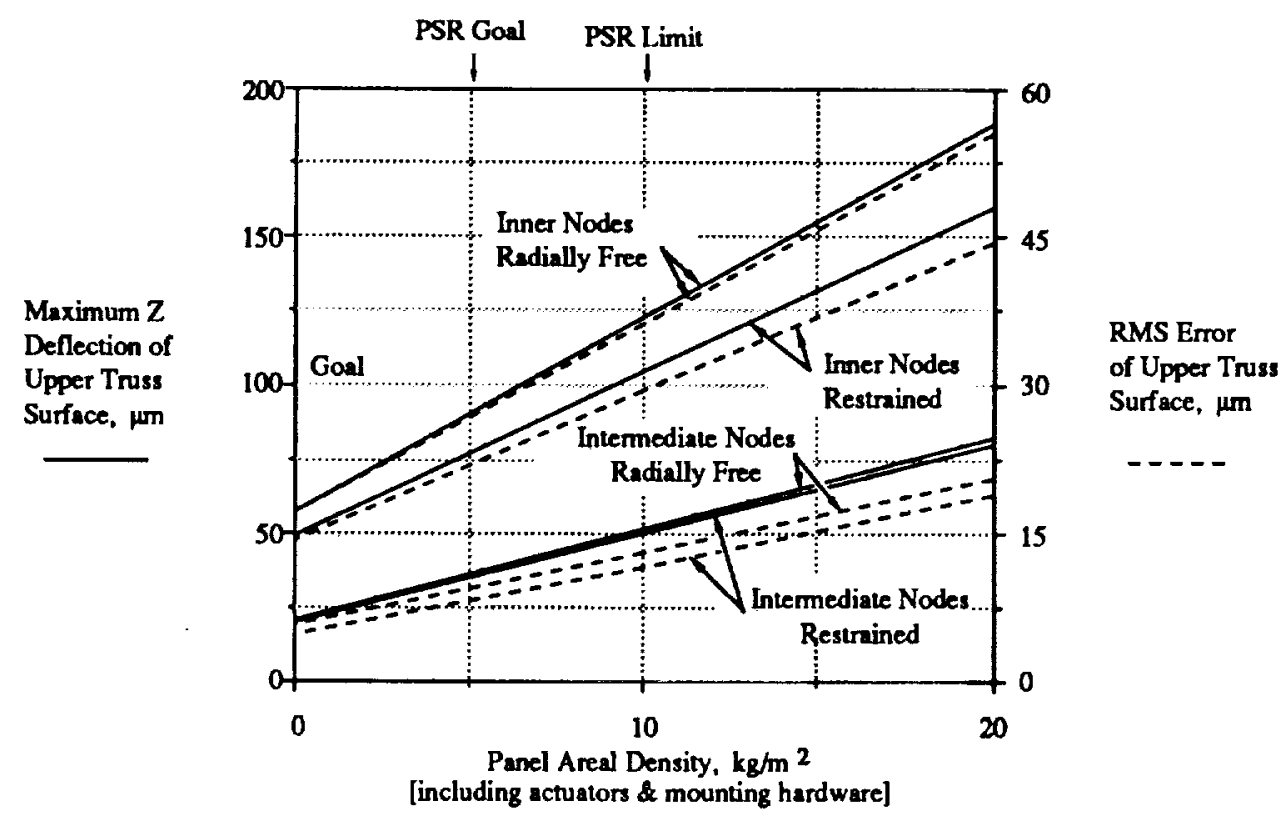

Figure 12. Gravity load deflections as a function of panel areal density for the Test Bed without secondary optics.

5.3.3. Test Bed natural frequencies. The results of dynamic analyses of the Test Bed are presented in Figure 13. The initial analyses were performed with the secondary optical system removed. Results for the four boundary conditions previously described are included in the figure, along with the results of free-free analyses. For the restrained intermediate nodes support, the fundamental frequency is $63 \mathrm{~Hz}$ without panels, and $38 \mathrm{~Hz}$ after the addition of $10 \mathrm{~kg} / \mathrm{m}^{2}$ panels and mounting hardware. These frequencies are associated with rocking modes of the truss on its mounting structure. As with the static deflection results, the natural frequency predictions are relatively insensitive to the choice of restrained or radially free support conditions.

The effect of adding the secondary optics and tripod to the Test Bed with $10 \mathrm{~kg} / \mathrm{m}^{2}$ panels and actuators was examined for the restrained intermediate nodes support case. Table 1 shows the ratio of tripod element strain energy to total element strain energy for the first ten natural frequencies. As indicated in the table, the first six natural modes of the complete Test Bed model are dominated by the tripod supports and the secondary optical system. These first six modes involve torsion and rocking of the secondary mass and bending of the tripod support struts. The low frequencies associated with the secondary optical system are due largely to the low natural frequencies of the tripod struts. The tripod frequencies can be raised somewhat by fabricating the secondary tripod struts from higher modulus graphite. However, it was found that even if the graphite modulus is doubled, the lower modes are still dominated by the secondary optical system and its tripod struts. This situation may have important implications for an active figure control system. Alternate designs for the secondary optical support system may reduce but probably will not eliminate the strong influence of the secondary optical system on the dynamics of the Test Bcd. 


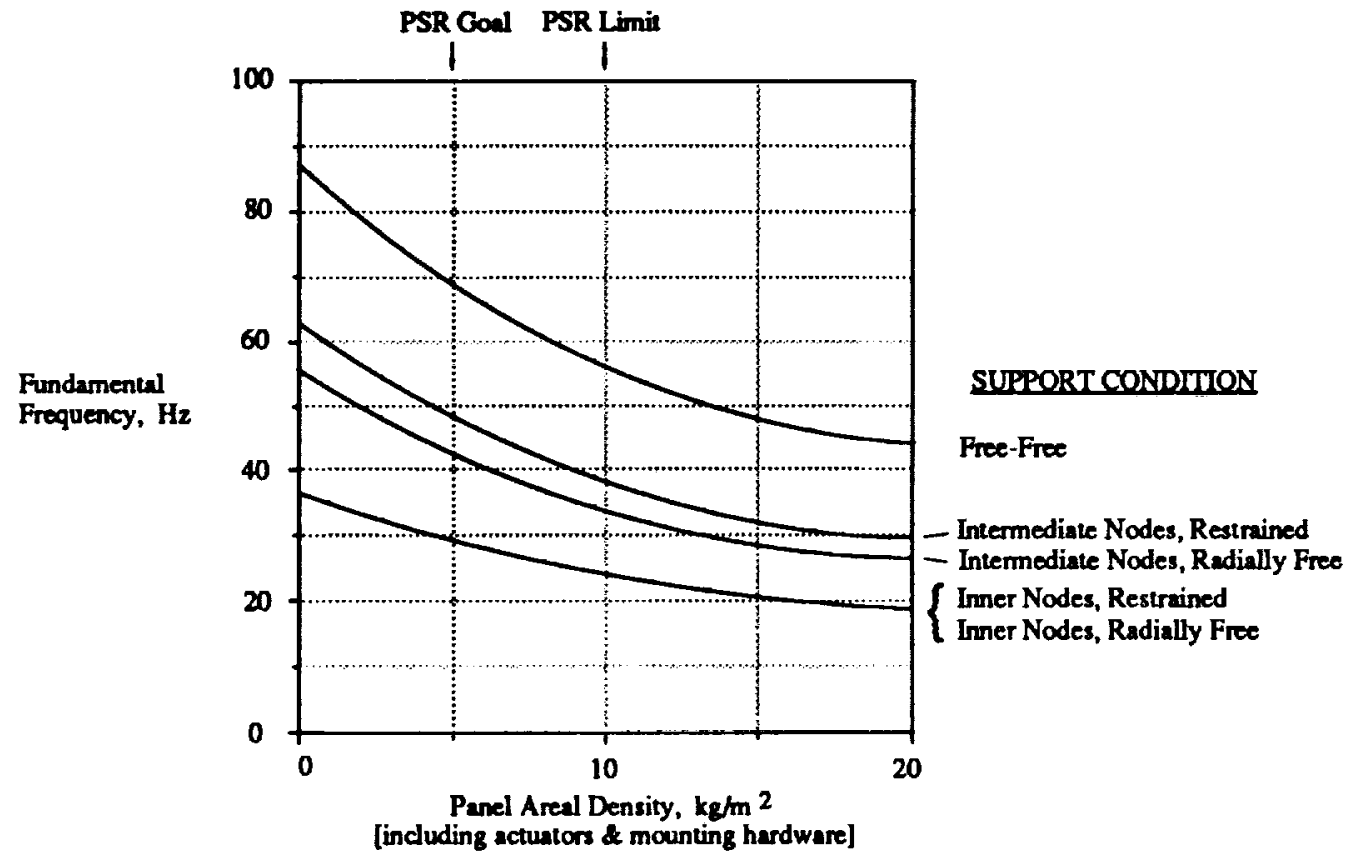

Figure 13. Fundamental frequencies as a function of panel areal density for the Test Bed without secondary optics.

\begin{tabular}{|ccc|}
\hline & & TRIPOD STRANN ENERGY \\
MODE & FREQUENCY, HZ & TOTAL STRAN ENERGY \\
1 & 14.5 & .999 \\
2 & 15.4 & .997 \\
3 & 15.4 & .997 \\
4 & 24.9 & .991 \\
5 & 24.9 & .991 \\
6 & 25.0 & .999 \\
7 & 29.8 & .168 \\
8 & 29.8 & .168 \\
9 & 43.6 & .998 \\
10 & 44.4 & .111 \\
(Internediale Nodes Restrained, Areal Densily Pmels and Actuators $=10 \mathrm{~kg} / \mathrm{m}^{2}$ )
\end{tabular}

Table 1. First ten natural frequencies and tripod strain energies for Test Bed with secondary optics. 


\section{MODELING AND ANALYSIS OF LARGE PSR SUPPORT STRUCTURES}

In this section models of 20-meter-diameter erectable and deployable support structures are described and analytical results arc presented. Also, relevant similarities and differences between the 20-meter models and the Test Bed model are discussed.

\section{1._LDR as a typical system configuration for large PSR support structures}

A brief description of the Large Deployable Reflector as it is related to the PSR program was given in section 1, and a sketch of one possible LDR configuration was shown in Figure 1. Because several LDR design parameters have been defined, it is convenient to examine the behavior of large PSR support structures by considering them to be part of an LDRlike system. The primary goal of the analyses presented here was to gain some insight into the global behavior of large truss structures that might be used for any PSR application. To accomplish this, models of two 20-meter support structures were constructed, one erectable and one deployable.

The truss designs were based on the erectable and deployable support truss concepts described in section 3, using a 2.0 meter basic strut length. For the erectable truss all core struts had a length of $2 \mathbf{m}$ with surface strut lengths differing slightly from this value. For the deployable truss, the vertical core struts and the radial struts of the single fold beams were $2 \mathrm{~m}$ long. The core strut length of $2 \mathrm{~m}$ results in a truss depth of $2 \mathrm{~m}$ for the deployable truss and $1.7 \mathrm{~m}$ for the erectable truss. The basic strut length of $2 \mathrm{~m}$ yields reflector panels that have an approximate maximum dimension of $2 \mathrm{~m}$, which is the size anticipated for LDR panels. The PSR areal density goal of $5 \mathrm{~kg} / \mathrm{m}^{2}$ for the panels and mounting hardware was assumed for the analyses presented here. Assuming this areal density, the mass of the reflector panels and mounting hardware will be approximately $1407 \mathrm{~kg}$. No additional areal density was included for actuators or other panel utilities since LDR is baselined to have an active primary.

In addition to reflector panels, the LDR support truss must also interface with a sunshade, an instrument module, and a central optical system. The instrument module is located at the base of the truss (sce Figure 1). Note that the term "instrument module" as used here includes all instruments at the base of the reflector, including any "resource modulc", "tclescope support module" or other subsystem commonly associated with LDR (sec, for example, reference 4). The mass properties for these LDR components are not well defined. The mass values shown in Figure 1 represent values based on estimates taken from references 3 and 4 . The mass estimate of $2500 \mathrm{~kg}$ for the sunshade includes the shade material and its support hardware. This estimate is conservative in comparison with those of reference 3 . 


\subsection{Finite element models of large PSR supoort structures}

The struts in the 20-meter models were assumed to have an outer diameter of $2.5 \mathrm{~cm}$, approximately the same as the Test Bed struts. Both the erectable and deployable support trusses were assumed to consist of three strut types, each having a different wall thickness. The first (innermost) ring of truss contained struts with a wall thickness of $5 \mathrm{~mm}$. The second ring contained struts with a wall thickness $3 \mathrm{~mm}$. Struts in rings three through five had a wall thickness of $1 \mathrm{~mm}$. This "tapered" truss design was derived from analyses described in reference 1, which showed that for a large truss attached to a massive central body, the greatest amount of static or dynamic deformation results from straining of the inner rings.

Finite element models were constructed for both the erectable and deployable structures. Modeling of these larger structures involved some simplifying assumptions which were not made for the Test Bed. For example, effective stiffness values were not calculated for each strut. Instead, the struts were assumed to be fabricated from graphite/epoxy having a unidirectional modulus of $2.68 \times 10^{11} \mathrm{~N} / \mathrm{m}^{2}$ (39 million psi), approximately twice as great as the modulus used for the Test Bed. Pitch 75 (P75) graphite, for example, has a modulus close to this value. To account for the lower stiffness of the joints and nodes, a modulus "knockdown factor" of $15 \%$ was applied to both structures, yielding an effective modulus for each strut of $2.28 \times 10^{11} \mathrm{~N} / \mathrm{m}^{2}$. Note that this knockdown in strut stiffness is slightly greater than the $10 \%$ reduction calculated for the Test Bed in section 5.2. No additional knockdown was assigned to account for the hinges in the deployable structure. This assumption, which is probably optimistic, was made because the stiffness properties of the deployable joints and hinges are not well known.

If the joints and nodes used with a thick-walled strut $(5 \mathrm{~mm})$ were the same as those used with a thin-walled strut $(1 \mathrm{~mm})$ of the same length, then the modulus knockdown required to obtain the correct effective stiffness should be greater for the thick walled strut (this can be seen by examining Equation 1). Using the same knockdown (15\%) for each strut assumes that the innermost joints are stiffer than those in the outer rings. In other words, the joints and nodes are assumed to be tapered in the same manner as the strut wall thicknesses. This would be done to ensure that the benefit of using thicker-walled struts in the inner rings is not compromised by the flexibility of the joints and nodes. The joints near the inner rings might be stiffened by either adding mass or using a higher-modulus material. The practical details of such a design have not been worked out. Nevertheless, it is a desirable goal and is one of the assumptions made here.

The density of the graphitc/epoxy struts was assumed to be $1740 \mathrm{~kg} / \mathrm{m}^{3}$, also consistent with P75 graphite. To account for the mass of the joints and nodes it was assumed that the graphite/epoxy tubes account for half of the total structural mass, while the remaining half is accounted for by the nodes and joints (this assumption can be shown to be approximately true for a five-ring 20-meter truss with aluminum joints and nodes). The mass of the joints and nodes was accounted for by using an effoctive density twice as great as the actual tube density. Thus, a density of $3480 \mathrm{~kg} / \mathrm{m}^{3}$ was used in both the erectable and deployable models. This density yields predicted mass values of $693 \mathrm{~kg}$ for the erectable truss and $941 \mathrm{~kg}$ for 
the deployable. Using the total reflector surface area $\left(281 \mathrm{~m}^{2}\right.$ for the present models) to approximate the truss surface area, the areal truss densities are $2.5 \mathrm{~kg} / \mathrm{m}^{2}$ and $3.3 \mathrm{~kg} / \mathrm{m}^{2}$ for the erectable and deployable trusses, respectively. These values meet the PSR design goal of $5 \mathrm{~kg} / \mathrm{m}^{2}$, and they are significantly lower than the value of $8.1 \mathrm{~kg} / \mathrm{m}^{2}$ given in section 5.1 for the Test Bed. The lower areal densities for the 20-meter trusses are due to the longer strut lengths which reduce the number of nodes and joints in a given volume of truss. Because the struts in the inner rings had thicker walls than those in the outer rings, more mass was assigned to the finite element nodes of these struts. This result is consistent with the previously stated assumption that the nodes and joints in the inner rings are stiffer than those in the outer rings.

The mass of the reflector panels was incorporated into the 20-meter models using the same method that was used for the Test Bed (see section 5.2). Again, the flexibility of panel mounting hardware was not included. The instrument module and central optical system (or center body; see Figure 1) were modeled as rigid cylinders with masses of $9000 \mathrm{~kg}$ and $1000 \mathrm{~kg}$, respectively. Inertia properties were assigned by estimating the diameter and length of each cylinder from the LDR baseline geometry. The sunshade was not modeled as a flexible body; instead, $2500 \mathrm{~kg}$ of mass was lumped at the upper surface nodes at the outer rim of each truss. This approach precludes prediction of local panel or sunshade modes and of their coupling with support truss modes. The goal here is not to construct detailed LDR models nor to predict LDR behavior, but merely to obtain estimates of the behavior of large support structures that might be used for PSR applications.

\subsection{Analysis of large PSR support trusses}

The results of three analyses of the erectable and deployable 20-meter-diameter support trusses are presented here: static deflection under gravity loading, deflection due to a constant angular slewing acceleration, and free-free vibration frequencies. For each case, the loading and support conditions are defined, followed by the analysis results, Again, I-DEAS Supertab was used to construct the models and interrogate results, while MSC/NASTRAN was used to perform the analyses.

6.3.1. Static deflection of large PSR trusses under gravity loading. The method of support for a 20-meter structure during ground testing has not been determined. For the analyses presented here, it was assumed that each structure was supported at its lower surface. Because of their size and weight, supporting them at the innermost lower nodes as was done for the Test Bed may not be desirable. Thus, only intermediate node support locations were examined, as shown in Figure 14. The support locations were chosen to lie approximately midway between the center and outer rim of each lower Iruss surface. It was assumed that each support node was in a radially free condition as described previously (section 5.3.1) for the Test Bed. The rigid center body shown in Figure 14 was considered important only for operational configurations, and thus was not included in the gravily loading analyses. 


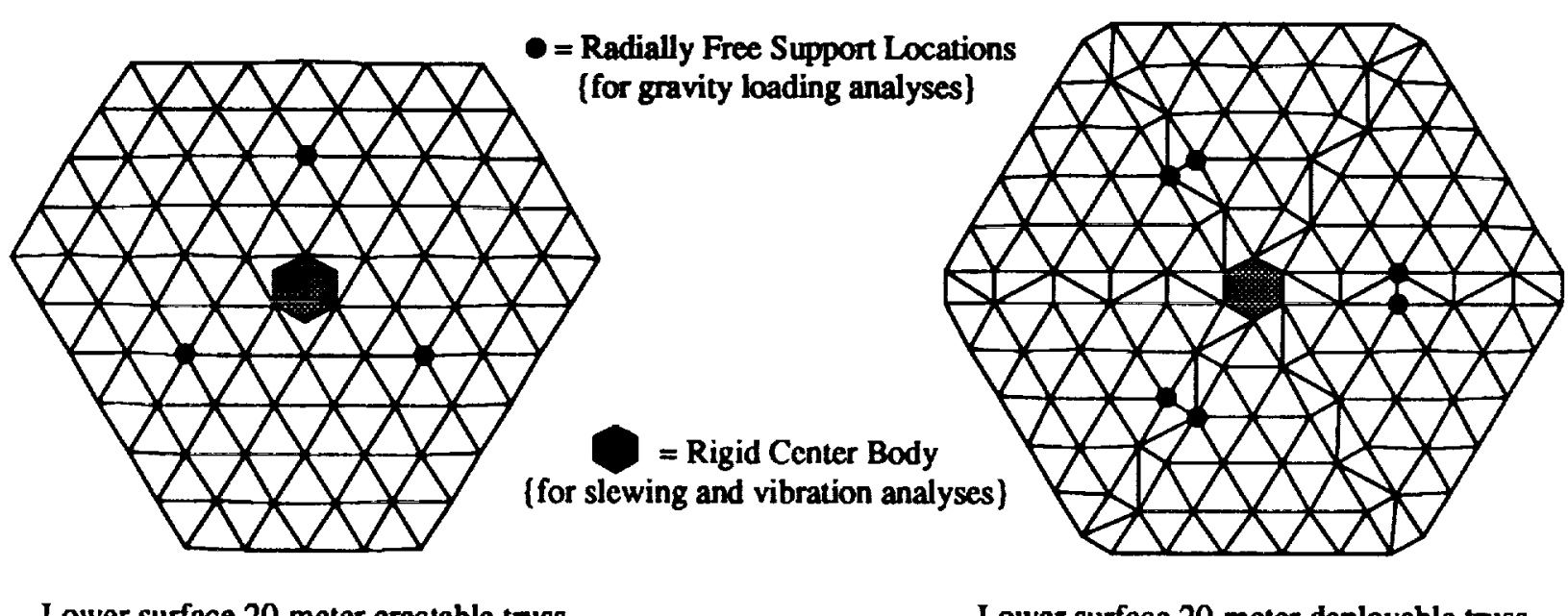

Lower surface 20-meter erectable truss

Lower surface 20-meter deployable truss

Figure 14. Support nodes and rigid center body assumed for 20-meter truss analyses.

The maximum deflection of the upper truss surface under gravity loading for both the erectable and deployable support trusses is shown in Figure 15. Deflections are shown for each truss with and without the reflector panels and mounting hardware. Without the panels, the erectable truss deflects $300 \mu \mathrm{m}$ and the deployable truss deflects $400 \mu \mathrm{m}$. It is noted that gravity loading is probably much more severe than any expected operational loading. Thus, it is encouraging that the maximum deflections for the trusses without panels is only three to four times as great as the $100 \mu \mathrm{m}$ goal for PSR. It scems reasonable to expect that, with careful fabrication and ground testing, the $100 \mu \mathrm{m}$ goal for an operational environment can be met. When the panel mass is included, each structure deflects approximately $1100 \mu \mathrm{m}$. The results in Figure 15 indicate that for a given increase in loading, the corresponding increase in deflection is slightly less for the deployable truss than for the erectable truss. This is largely due to differences in the truss depths and support conditions. If surface accuracy is of primary importance, the support conditions shown in Figure 14 might be undesirable for the 20-meter structures, because the maximum deflections are above the $100 \mu \mathrm{m}$ limit for PSR. Hence, a more complicated support system involving numerous nodes on either the lower or upper truss surfaces might be necessary.

\subsubsection{Deflections of large PSR trusses subiected to slewing angular accelerations. To examine}

behavior under operational loading, the models were used to simulate subjecting each 20-meter truss to constant angular (slewing) accelerations of .001 rad/ $/ \mathrm{sec}^{2}$. As discussed in section 4, this is a conservative estimate of operational loading. The slewing was about an axis perpendicular to the optical axis of the reflector surface. The trusses were assumed to be attached to a rigid hexagonal center body as shown in Figure 14. For the erectable truss the center body was attached to three nodes on the upper surface and three nodes on the lower surface. For the deployable truss, the center body was attached to six nodes on the upper surface and six on the lower surface. The accelerations were applied by using the "inertia relief" capability of MSC/NASTRAN ${ }^{5}$. Using this technique, accelerations due to an applied load are computed and the resulting 
inertia forces are distributed to all node points. The singularities which result from rigid body motion are removed and the resulting displacements caused by the inertia forces are then calculated.

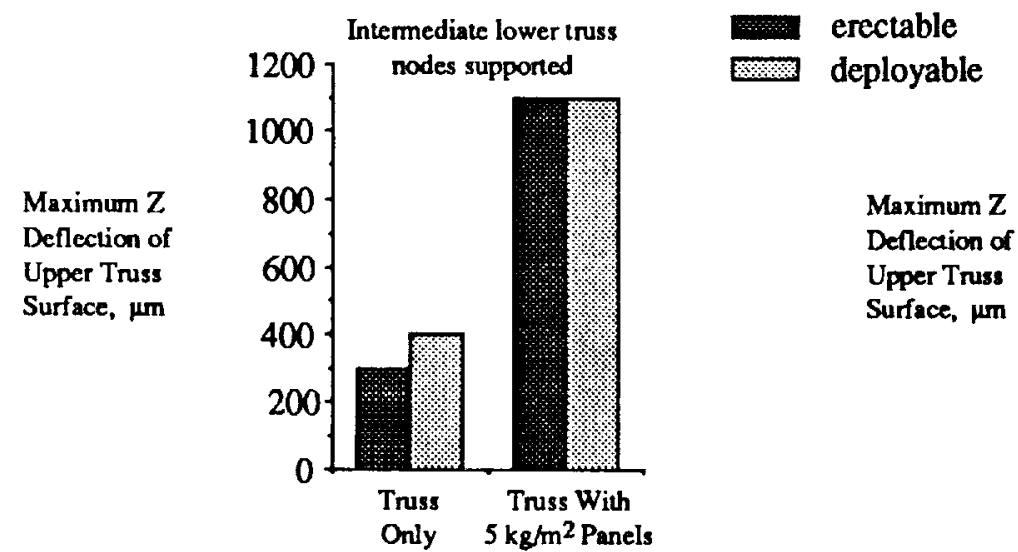

Figure 15. Static deflection of 20-meter trusses under gravity loading.

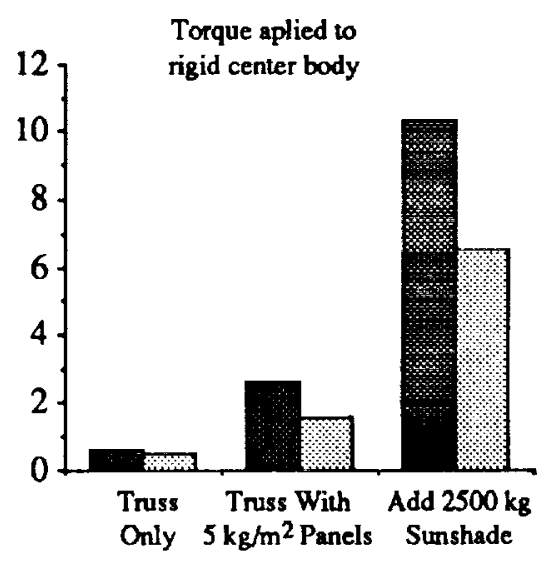

Figure 16. Maximum deflection of 20-meter trusses subjected to $.001 \mathrm{rad} / \mathrm{sec}^{2}$ slewing acceleration.

When subjected to the slewing acceleration each truss experienced its maximum deflection at the outer rim of the structure. The maximum deflections are shown in Figure 16. It is noted that these results neglect any effect on slewing response of the sunshade and center body flexibilities. For the truss only (without panels or sunshade), the maximum deflection is $.65 \mu \mathrm{m}$ for the erectable truss and $.51 \mu \mathrm{m}$ for the deployable truss. When the panels and sunshade are added to the structures, the maximum deflection increases to $10.3 \mu \mathrm{m}$ for the erectable truss and $6.5 \mu \mathrm{m}$ for the deployable. The larger increase in deflection for the erectable structure is largely due to the fact that it is mounted to the rigid center body at fewer node points. These results indicate the important influence of the sunshade on the truss response to slewing loads, and suggests the necd for a detailed sunshade model. For the operational loads considered, the truss surface deflections are only a fraction of the $100 \mu \mathrm{m}$ limit set for LDR and PSR.

6.3.3. Free-free natural frequencies of large PSR trusses. The free-free vibration frequencies of the 20-meterdiameter trusses were determined and are shown in Figure 17. For each case shown in the figure a panel mass of $5 \mathrm{~kg} / \mathrm{m}^{2}$ was assumed. Figure 17 shows flexible modes (non-rigid body modes) one and six for three analysis cases. On the left side of the figure are the modes for each truss without a rigid center body. For this case, the frequency of the first flexible mode is $14.2 \mathrm{~Hz}$ for the crectable truss and $15.6 \mathrm{~Hz}$ for the deployable truss. The frequencies of the sixth flexible mode are 34.8 $\mathrm{Hz}$ and $36.6 \mathrm{~Hz}$, respectively. Adding a rigid center body of mass $10,000 \mathrm{~kg}$ (the estimated value for LDR) did not significantly change the mode 1 frequencies but the mode 6 frequencies decreased, as shown in Figure 17. As might be expected, the effect of adding a rigid center body cannot be predicted by examining only the first flexible modes. 


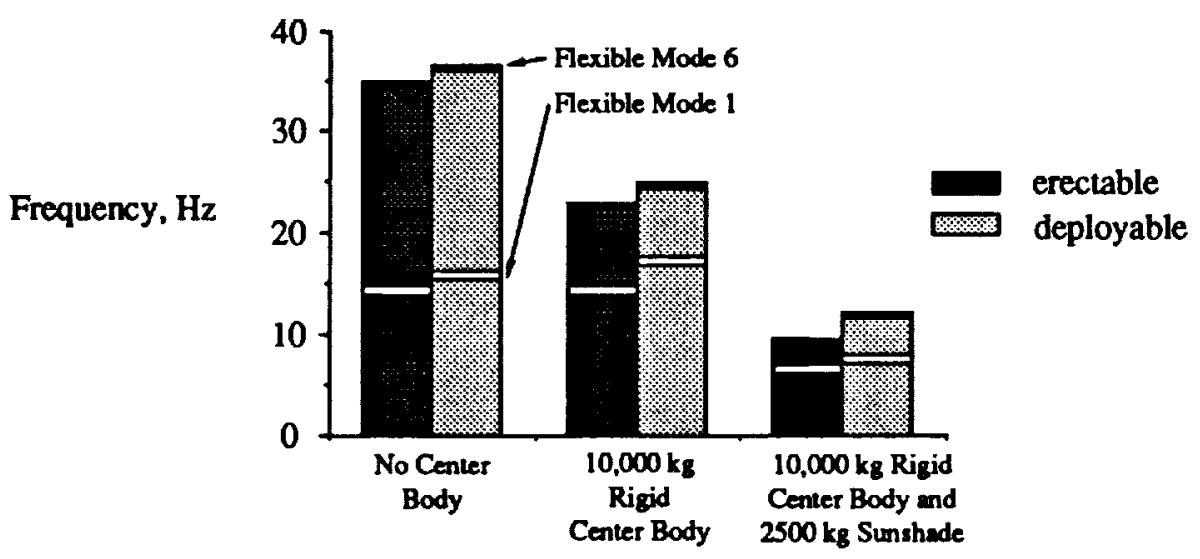

Figure 17. Free-free vibration frequencies of 20 -meter trusses with $5 \mathrm{~kg} / \mathrm{m}^{2}$ panels.

On the right side of Figure 17 are calculated frequencies for the two truss structures with the $2500 \mathrm{~kg}$ sunshade included. These results assume insignificant coupling between the truss and sunshade modes. For this case, the first modal frequency is $6.8 \mathrm{~Hz}$ for the erectable truss and $7.5 \mathrm{~Hz}$ for the deployable truss. Adding the sunshade mass further reduces the first mode frequencies, as well as the range of frequencies spanned by the first six modes. These frequencies appear to be high for such large and massive structures, which should allow for the design of adequate control systems. They give an indication of the stiffness that is possible for large PSR structures.

As stated in section 4, one of the Test Bed functional requirements is that it have LDR-like dynamic characteristics. For the complete 20-meter structures (right side of Figure 17), the first and second flexible modes are second-order modes (two diametrical node lines) with frequencies close to $7 \mathrm{~Hz}$, while for the Test Bed with restrained intermediate nodes and $10 \mathrm{~kg} / \mathrm{m}^{2}$ panels and actuators they are first-order rocking modes with a frequency of $38 \mathrm{~Hz}$ (see Figure 13). If matching frequencies is of primary importance, the lowest Test Bed frequencies may be close enough to those of an LDR-like structure to be useful. However, if matching mode shapes is of primary importance, these results indicate that it may be difficult to satisfy the requirement that the Test Bed be dynamically similar to LDR, since the first Test Bed mode shapes that resemble those of the second-order LDR-like modes occur at a frequency of $72 \mathrm{~Hz}$. It may be possible to better simulate LDR-like frequencies and mode shapes by placing additional mass at the outer rim of the Test Bed during dynamic testing.

\section{Z. DISCUSSION AND CONCLUSIONS}

In this paper, several design considerations and analyses relevant to the development of large precision reflectors have been outlined. The structures activities of NASA's Langley Research Center have been discussed and design concepts for erectable and deployable PSR support structures have been presented. Important functional requirements for these structures have been reviewed and analytical results related to mass, stiffness, dynamic behavior, and surface accuracy have been 
discussed. Results have been presented for the 4-meter diameter PSR Test Bed and for two large 20-meter-diameter support structures.

While the results give some insight into the expected accuracy and stiffness of PSR structures, they do not represent a final or complete analysis of PSR or LDR support structures. For example, this paper contains no discussions of truss distortions resulting from thermal loading or from any length errors in the manufactured struts. These and other issues are currently being studied by JPL and LaRC. In addition, the assumptions used in constructing the 20-meter-diameter support truss models have yielded only approximate and preliminary results. However, the models do provide a starting point for more refined and complete analyses. Experimental verification of the static behavior, dynamic behavior, and surface accuracy of PSR support structures is a future goal.

The results presented here lead to the following conclusions which relate directly to the PSR support truss requirements given in section 4:

(1) The areal density of the Test Bed truss is expected to be $8.1 \mathrm{~kg} / \mathrm{m}^{2}$, higher than the goal of $5 \mathrm{~kg} / \mathrm{m}^{2} \mathrm{but}$ less than the upper limit of $10 \mathrm{~kg} / \mathrm{m}^{2}$. Truss areal densities that meet the PSR design goal of $5 \mathrm{~kg} / \mathrm{m}^{2}$ should be possible for larger structures which contain longer struts and have a smaller percentage of joint and node mass for a given volume of truss.

(2) To minimize the distortion of the Test Bed mounted at three support nodes during ground testing, a mounting fixture which supports the truss at the intermediate lower surface nodes should be utilized. If this type of support is used for the truss and secondary optical system, gravity sag is predicted to contribute less than $20 \mu \mathrm{m}$ to the total rms surface error.

(3) Both deflection and frequency results are relatively insensitive to the difference between radially free and restrained support conditions.

(4) If the Test Bed secondary optical system is mounted to a simple tripod support structure that complies with the current blockage requirement, the lowest vibration modes are likely to be dominated by rocking and torsion of the secondary system.

(5) Ground testing of large PSR support structures will require mounting to numcrous truss surface nodes if it is desirable to limit gravity distortions to less than $100 \mu \mathrm{m}$. However, the analysis results indicate that for the case of a 20 -meterdiameter truss (without pancls) supported at only three lower surface nodes, the maximum displacement due to gravity loading is only three to four times as great as the PSR design goal of $100 \mu \mathrm{m}$.

(6) Slewing loading of PSR support structures should create truss surface distortions which are far below the $100 \mu \mathrm{m}$ limit set for PSR. Analysis indicates that a sunshade would have an important influence on truss response to slewing loads, and suggests the need for a detailed sunshade model.

(7) Free-free vibration frequencies of approximately $7 \mathrm{~Hz}$ are predicted for 20-meter PSR support trusses in an LDR-like system configuration. 
(8) Simulating LDR-like dynamic characteristics using the Test Bed will be difficult. Matching lowest frequencies may be possible by adding mass to the Test Bed structure during dynamic testing; matching mode shapes will be more difficult, if possible at all.

\section{REEERENCES}

1. J.M. Hedgepeth, Pactruss Support Structure for Precision Segmented Reflectors. NASA CR-181747 (1989).

2. H.G. Bush, M.S. Lake, J.J. Watson, and W.L. Heard Jr., The Versatility of a Truss Mounted Mobile Transporter for In-Space Construction. NASA Technical Memorandum 101514, pp. 4-5, NASA Langley Research Center (1988).

3. Large Deployable Reflector (IDR) Reference Concept. Final Report JPL Contract 957514, pp. 3-2,5-4, Lockheed Missiles and Space Company, Inc., LMSC-F230421 (1987).

4. P.N. Swanson, A Lightweight Low Cost Large Deployable Reflector (LDR): A Concept Study by the Jet Propulsion Laboratory, JPL D-2283, pp. 2-8 - 2-14, Jet Propulsion Laboratory (1985).

5. H.G. Schaeffer, MSCNASTRAN Primer: Static and Normal Modes Analysis, pp. 309-310, Schaeffer Analysis Inc., Mont Vernon, NH (1979). 


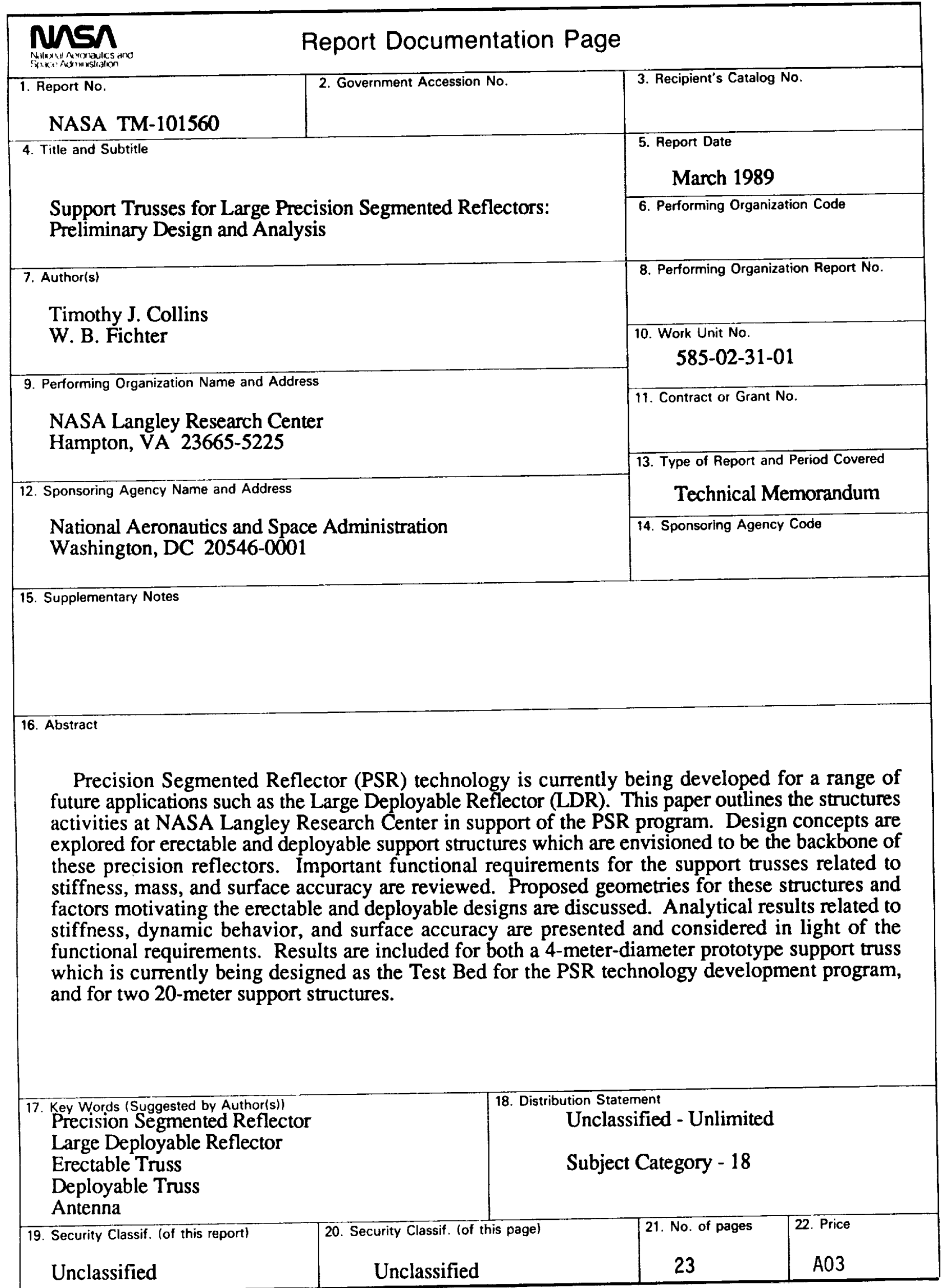


